\title{
ANALISIS KEUNTUNGAN PEMELIHARAAN TERNAK SAPI DI KECAMATAN SULUUN TARERAN KABUPATEN MINAHASA SELATAN
}

\author{
Jimmy Ch. Tumober* A.Makalew**, A.H.S Salendu**), E.K.M. Endoh** \\ Fakultas Peternakan Universitas Sam Ratulangi Manado, 95115
}

\begin{abstract}
ABSTRAK
Umumnya masyarakat Kecamatan Suluun Tareran berprofesi sebagai petani/peternak. Populasi ternak sapi di daerah ini sebanyak 308 ekor yang tersebar di 8 desa. Masalahnya berapa besar biaya produksi (pakan, tenaga kerja dan obat-obatan/vitamin) berpengaruh terhadap keuntungan dalam pemeliharaan ternak sapi di daerah ini. Tujuan penelitian ini adalah untuk mengetahui berapa besar pengaruh biaya produksi (pakan, tenaga kerja dan obatobatan/vitamin) dalam pemeliharaan ternak sapi di Kecamatan Suluun Tareran Kabupaten Minahasa Selatan. Penelitian ini dilaksanakan dengan menggunakan metode survey. Data dalam penelitian ini diperoleh dari 2 sumber yaitu data primer dan data sekunder. Metode penentuan sampel lokasi dan responden dilakukan secara Purposive Sampling. Jumlah responden sebanyak 30 petani peternak. Hasil penelitian menunjukkan bahwa pada umumnya rumput yang dikonsumsi ternak sapi tidak dibeli, hanya pada musim-musim tertentu saja petani peternak membeli rumput misalnya pada musim kemarau. Berdasarkan hasil penelitian dapat disimpulkan bahwa biaya produksi dalam pemeliharan ternak sapi di lokasi penelitian rata-rata sebesar Rp. 6,756,215,67 per tahun untuk pemeliharan 3-4 ekor yang meliputi biaya pakan $(50,20 \%)$, biaya tenaga kerja $(46,36 \%)$ dan biaya obat-
\end{abstract}

\footnotetext{
*Alumni Fakultas Peternakan Unsrat **Jurusan Sosial Ekonomi Peternakan
}

batan/vitamin $(1,44 \%)$. Biaya produksi berpengaruh nyata pada tingkat signifikan 99\% $\left(\mathrm{t}_{\text {hit }}=0,0003\right)$ terhadap tingkat keuntungan ternak sapi di Kecamatan Suluun Tareran.

Kata Kunci : Biaya Produksi, Keuntungan, Ternak Sapi

\section{ABSTRACT}

PROFIT ANALYSIS OF BEEF FARMING AROUND SULUUN TARERAN DISTRICT IN SOUTH MINAHASA REGENCY. Generally, communities of Suluun Tareran district were household farmers. Beef cattle populations in this area were about 308 head spreading at eight villages. The problem was how much the production cost (feeding, labor, and other feed supplement) do affect the profit of beef farming around this area. The objective of this study was to evaluate effect of production cost on income and profit of beef farming system in Suluun Tareran district of South Minahasa regency. Research was conducted using survey method. Data were found from two sources including primer and secondary data sources. Samples of respondence were determined by purposive sampling method. The total of 30 household farmers were used in this study. Results showed that grass feeding of the animals was not bought by farmers, except in dry season. Average production cost of beef cattle at research location were Rp. 
$6,756,215,67$ per year of 3-4 animals consisted of feed cost $(50,20 \%)$, labor cost $(46,36 \%)$ and feed supplement $(1,44 \%)$. Production cost affected significantly $\left(\mathrm{t}_{\text {calc. }}=0.0003\right)$ profit level of beef cattle farming in Suluun Tareran district.

Key word: Production cost, profit level, beef cattle farming, Suluun Tareran district.

\section{PENDAHULUAN}

Ternak sapi merupakan salah satu ternak yang produksi utamanya adalah daging, susu, dan kulit. Usaha peternakan sapi akhir-akhir ini telah memperlihatkan perkembangan yang pesat dan memberikan sumbangan ekonomi yang sangat besar (Susilorini, 2000 dan Suratyah, 2009). Selain sebagai penghasil daging, ternak sapi di Indonesia juga digunakan sebagai sumber tenaga kerja, bahan pupuk organik, biogas, dan tabungan dimasa yang akan datang (Susilorini, 2000).

Usaha peternakan sapi di Sulawesi Utara umumnya masih bersifat usaha peternakan rakyat. Pemeliharaanya masih sebatas usaha sampingan bagi usaha tani dan sebagai tabungan. Hal ini dikarenakan pada saat-saat tertentu, ketika petani memerlukan uang dalam memenuhi kebutuhan yang mendesak maka ternak sapi tersebut dapat diuangkan (Elly, 2008).

Umumnya masyarakat di Kecamatan Suluun Tareran berprofesi sebagai petani. Salah satu jenis ternak yang banyak dipelihara oleh masyarakat petani daerah ini ialah ternak sapi. Berdasarkan data hasil survei yang diambil dari Balai Penyuluhan Pertanian Perikanan dan Kehutahan (BP3K) Kecamatan Suluun Tareran tahun 2012, menyatakan bahwa populasi ternak sapi berjumlah 308 ekor yang tersebar di 8 desa populasi ternak sapi terbesar terdapat pada Desa Suluun III, Desa Suluun IV, dan Desa Suluun I.

Pemeliharaan ternak sapi di Wilayah ini masih dilakukan secara tradisional dengan sistem pemeliharaan secara ekstensif. Hal ini dibuktikan dari pengamatan secara langsung di lapangan bahwa ternak sapi dipelihara dengan cara mengikat ternak di lahan-lahan petani baik lahan terlantar maupun lahan yang baru selesai panen jagung ataupun tanaman musiman lainnya. Pola pemeliharaan yang bersifat sampingan sering membuat petani peternak kurang memperhatikan 
biaya yang dikeluarkan selama proses pemeliharan ternak sapi.

Berdasarkan pemikiran di atas maka perlu dilakukan penelitian mengenai berapa besar pengaruh biaya produksi (pakan, tenaga kerja dan obat-obatan/vitamin) dalam pemeliharaan ternak sapi di Kecamatan Suluun Tareran. Tujuan penelitian ini adalah untuk megetahui berapa besar pengaruh biaya produksi (pakan, tenaga kerja dan obat-obatan/vitamin) dalam pemeliharaan ternak sapi di

Kecamatan Suluun Tareran.

\section{METODE DAN MATERI PENELITIAN}

Penelitian ini dilaksanakan di $\begin{array}{lrr}\text { Kecamatan } & \text { Suluun } & \text { Tareran } \\ \text { Kabupaten } & \text { Minahasa } & \text { Selatan. } \\ \text { Penelitian } & \text { dilakukan } & \text { dengan } \\ \text { menggunakan } & \text { metode } & \text { survei. }\end{array}$ Sumber data yang dikumpulkan yaitu data primer dan data sekunder.Data primer diperoleh melalui wawancara langsung pada responden yang berpedoman pada daftar pertanyaan yang sudah dibuat. Sedangkan data sekunder bersumber dari instansiinstansi terkait yakni kantor BP3K Suluun Kecamatan Suluun Tareran Tahun 2012.
Penentuan sampel lokasi penelitian dilakukan berdasarkan metode purposive sampling dengan kriteria lokasi yang memiliki populasi ternak sapi terbanyak di Kecamatan Suluun Tareran yakni di desa Suluun 1, 2, 3 dan 4. Pengambilan sampel responden sebanyak 30 responden dilakukan secara purposive sampling dengan kriteria responden : (1) Memiliki ternak sapi dewasa $\geq 2$ ekor; (2) Memiliki pengalaman berternak $\geq 3$ tahun; dan (3) Pernah menjual ternak sapi dalam 2 tahun terakhir.

Definisi variabel dan pengukurannya dalam penelitian ini : (1) Pemilikan ternak sapi ialah keseluruhan jumlah ternak sapi baik jantan maupun betina yang dimiliki oleh petani peternak (responden), diukur dalam satuan ekor; (2) Biaya pakan ialah keseluruhan biaya pakan yang dikeluarkan dalam proses produksi ternak sapi (hijauan/rumput lapangan ataupun pakan tambahan seperti dedak halus), diukur dalam satuan rupiah per tahun; (3) Biaya tenaga kerja ialah jumlah biaya yang dikeluarkan untuk membayar tenaga kerja yang bekerja dalam proses produksi memelihara ternak sapi, 
(menyewa) dalam keluarga kali upah yang diukur dalam satuan rupiah per tahun; (4) Biaya obat-obatan dan vaksin ialah jumlah keseluruhan uang yang digunakan untuk membayar obat dan vaksin dalam proses pemeliharaan ternak sapi, diukur dalam satuan rupiah per tahun; (5) Tenaga kerja ialah tenaga kerja keluarga yang bekerja dalam proses produksi ternak sapi diukur dalam satuan jam kerja per tahun; (6) Penerimaan ialah nilai uang yang diterima dari hasil penjualan ternak sapi, hasil sewa tenaga kerja ternak dan hasil ikutan (pembibitan), diukur dalam satuan rupiah per tahun; (7) Keuntungan ialah seluruh jumlah penerimaan dari usaha pemeliharaan ternak sapi dikurangi dengan seluruh biaya pemeliharaan, diukur dalam satuan rupiah per tahun. Data yang dikumpulkan ditabulasi dan dianalisis dengan menggunakan pendekatan analisis deskriptif dan matematik. Pendekatan analisis deskriptif dimaksudkan untuk menguraikan secara kualitatif keadaan riil usaha pemeliharaan ternak sapi yang diformulasikan dalam bentuk tabelaris ataupun persentase. Analisis pengaruh biaya produksi pada usaha pemeliharaan ternak sapi terhadap tingkat keuntungan menggunakan pendekatan model analisis regresi sederhana (Simple Regression) menurut formulasi Gujarati (1995). Secara matematis hubungan fungsinya sebagai berikut :

$\mathrm{Y}=\mathrm{b}_{0}+\mathrm{b}_{\mathrm{i}} \mathrm{X}+\mathrm{e}_{\mathrm{i}} \ldots \ldots \ldots \ldots \ldots \ldots$

Keterangan :

$\mathrm{Y}=$ Keuntungan usaha pemeliharaan ternak sapi

$\mathrm{X}=$ Biaya produksi usaha pemeliharaan ternak sapi

$\mathrm{b}_{0}=$ Intersep (koefisien konstanta)

$b_{i}=$ Koefisien parameter yang diestimasi

$\mathrm{e}_{\mathrm{i}}=$ Error (kesalahan pengamatan)

\section{HASIL DAN PEMBAHASAN}

Hasil penelitian menunjukan bahwa umur responden bervariasi dari umur 38-70 tahun dengan rincian seperti disajikan pada Tabel 1. Data Tabel 1 menunjukan bahwa sebagian besar responden masih golong kelompok umur produktif yakni sebanyak 28 responden $(93 \%)$ dan hanya 2 responden $(6,66 \%)$ yang tidak tergolong kelompok usia produktif. Dirjen Peternakan (2003) mengatakan bahwa, umur produktif peternak antara 15-64 tahun.Umur 
seperti ini mempengaruhi seseorang dalam hal keterampilan dan pengalaman serta kemampuan dalam penyerapan teknologi.

Pendidikan merupakan hal yang sangat penting dalam

\section{Tabel 1. Jumlah Responden Berdasarkan Kelompok Umur}

\begin{tabular}{crrr}
\hline No & $\begin{array}{r}\text { Tingkatan } \\
\text { Umur(Tahun) }\end{array}$ & $\begin{array}{r}\text { Jumlah Responden } \\
\text { (Tahun) }\end{array}$ & Persentase (\%) \\
\hline 1 & $35-44$ & 2 & 6,66 \\
2 & $45-54$ & 15 & 50 \\
3 & $55-64$ & 11 & 36,6 \\
4 & $65-74$ & 2 & 6,66 \\
\hline Total & & 30 & 100 \\
\hline
\end{tabular}

pendidikan seseorang akan utama sebagai petani peternak mempengaruhi cara berpikir sehingga dalam bekerja selalu memperhitungkan pekerjaan yang menguntungkan. Tingkat pendidikan yang dimiliki responden beragam mulai dari tingkat SD, SMP, SMA, serta Perguruan Tinggi. Adapun tingkat pendidikan terbesar responden ada pada tingkat SD sebesar $33,33 \%$ sedangkan tingkat pendididkan terkecil pada tingkat Perguruan Tinggi sebesar 3,33\%.

Berdasarkan hasil penelitian sebanyak 27 responden atau sebesar 90 persen memiliki mata pencarian meningkatkan ketrampilan peternak khususnya tentang cara beternak yang baik, meliputi pemilihan bibit, pemberian makanan dan pengelolahan usaha. Pada umumnya 
usaha sampingan yang diperlukan untuk menambah penghasilan keluarga.Selain alasan tersebut, bahwa ternak sapi sebagai asset yang sewaktu-waktu dapat dijual sebagai modal pada saat ada kebutuhan yang mendesak.

Ternak sapi yang dimiliki merupakan ternak milik sendiri yang diperoleh dengan cara membeli atau bahkan ternak turunan. Jenis ternak sapi yang dipelihara oleh masyarakat Kecamatan Suluun Tareran adalah jenis sapi ongole.Pemilihan jenis sapi ongole didasarkan oleh tampilan fisik sapi yang besar sehingga cocok digunakan sebagai tenaga kerja. Selain itu, bangsa sapi ini tahan terhadap panas dan kualitas pakan yang jelek (Susilorini, 2000).

Usaha ternak sapi yang dimiliki oleh responden bervareasi antara 2 ekor sampai dengan 7 ekor per reponden. Jenis ternak sapi yamg dipelihara kebanyakan ialah ternak sapi jenis PO dan campuran sapi Bali. Jumlah keseluruhan pemilikan ternak sapi petani sampel sebanyak 114 ekor. Umur ternak sapi muda memiliki populasi yang terbanyak 55 ekor $(48,25 \%)$ diikuti umur ternak sapi dewasa sebanyak 51 ekor (44.74\%) dan umur ternak sapi anak (pedet) sebanyak 8 ekor $(7,02 \%)$. Hal ini berarti, pemilikkan ternak sapi oleh responden saat penelitian didominasi ternak muda dan dewasa. Biaya produksi dari usaha ternak sapi terdiri dari biaya pakan, biaya tenaga kerja dan biaya obatobatan/vitamin. Hasil penelitian menunjukkan bahwa rata-rata biaya produksi setiap peternak untuk pemeliharan ternak sapi rata 3-4 ekor sebesar Rp. 6,756,215,67 per tahun. Analisis biaya variabel usaha ternak sapai dapat dilihat pada Tabel 2 .

\section{Tabel 2. Analisis Biaya Variabel Usaha Ternak Sapi}

\begin{tabular}{llrr}
\hline No & Jenis biaya & $\begin{array}{r}\text { Jumlah biaya per } \\
\text { peternak }(\mathrm{Rp} / \mathrm{Thn})\end{array}$ & Persentase (\%) \\
\hline 1 & Biaya pakan & 3.467 .500 & 52,20 \\
2 & Biaya obat-obatan/vitamin & 95.000 & 1,44 \\
3 & Biaya tenaga kerja & $3.079,651$ & 46,36 \\
\hline & Total & 6.642 .151 & 100 \\
\hline
\end{tabular}


Data pada Tabel 2 menyatakan bahwa penerimaan menunjukkan bahwa biaya produksi terdiri dari biaya pakan, biaya tenaga kerja dan biaya obat-obatan/vaksin. Ketiga biaya ini dalam teori produksi dinyatakan sebagai biaya variabel. Biaya pakan merupakan biaya tertinggi $(52.20 \%)$. Berdasarkan beberapa hasil penelitian menunjukkan bahwa biaya pakan merupakan biaya tertinggi dari total biaya produksi (Elly, 2008). Umumnya penggunaan tenaga kerja manusia selama delapan jam dengan rata-rata operasi mulai dari jam 9 pagi sampai jam 5 sore (Bungi, 2008). Biaya tenaga kerja merupakan biaya terbesar kedua dalam penelitian ini yaitu sebesar $46.36 \%$. Sedangkan, biaya obat-obatan/vaksin adalah biaya terkecil dari total biaya produksi (1.44\%). Kecilnya biaya ini disebabkan petani jarang menggunakan obat dan vaksin dalam pemeliharaan ternak sapi.

Rata-rata penerimaan, biaya produksi dan keuntungan pada usaha ternak sapi dapat dilihat pada Tabel 3. Data pada Tabel 3 menunjukkan bahwa keuntungan yang diperoleh petani peternak $\mathrm{Rp}$ 33.932.118,33 per tahun. Hernanto (1993) usaha tani ternak adalah penerimaan dari seluruh sumber usaha tani ternak yang meliputi nilai penjualan hasil, panjualan inventaris, nilai produksi yang dikonsumsi petani dan keluarganya selama melakukan kegiatan. Kadarsan (1985), menambahkan penerimaan bersumber dari pemasaran atau penjualan hasil usaha seperti panen dan peternakan serta bahan olahannya. Keuntungan dalam penelitian ini diperoleh dari hasil penjualan ternak sapi, perkiraan penjualan ternak sapi dan penerimaan sewa ternak sapi dikurangi biaya produksi. Keuntungan merupakan faktor pengembalian atas usaha yang dilakukan untuk menghasilkan barang sebagai perangsang bagi usaha selanjutnya, menutup resiko dan segala sesuatu yang tidak pasti sebagai suatu alat dalam persaingan dan sebagai suatu nilai tambah (Sugeng, 2000).

Hasil analisis varian menunjukan bahwa biaya produksi berpengaruh nyata terhadap keuntungan peternak sapi di Kecamatan Suluun Tareran pada 
Tabel 3. Rata-rata Penerimaan, Biaya Produksi dan Keuntungan pada Usaha Ternak Sapi di Kecamatan Suluun Tareran

\begin{tabular}{llrc}
\hline No & \multicolumn{1}{c}{ Uraian } & $\begin{array}{l}\text { Rata-rata } \\
(\mathrm{Rp} / \mathrm{Thn})\end{array}$ & Persentase (\%) \\
\hline 1 & Penerimaan : & & \\
& Hasil penjualan ternak sapi & 9.786 .667 & 24,05 \\
& & 30.061 .667 & 73,88 \\
& Perkiraan penjualan ternak sapi & 840.000 & 2,06 \\
\hline & Penerimaan Sewa Ternak Sapi & 40.668 .334 & 100 \\
\hline & Total penerimaan & $6.756 .215,67$ & \\
\hline 2 & Biaya produksi & $33.932 .118,33$ & \\
\hline 3 & Total keuntungan (1-2) & & \\
\hline
\end{tabular}

tingkat siknifikan $95 \%\left(\mathrm{t}_{\text {hit }}=\right.$ 0,0003). Berdasarkan hasil analisis bahwa, biaya produksi dalam proses pemeliharan ternak sapi mempunyai hubungan yang cukup kuat terhadap tingkat keuntungan, hal ini diperlihatkan dengan nilai koefisien korelasi (r) sebesar 0,61, sedangkan nilai koefisien determinasi $(\mathrm{R})$ sebesar 0,38 , artinya variasi naik turunnya tingkat keuntungan petani peternak sapi dipengaruhi oleh biaya produksi (pakan, tenaga kerja dan obat-obatan/vitamin) sebesar $38 \%$. Kecilnya nilai koefisien determinasi tersebut disebabkan karena pemeliharaan ternak sapi bukan hanya dipengaruhi oleh biaya produksi (biaya pakan, biaya tenaga kerja dan biaya vaksin \& obatobatan) tetapi dipengaruhi juga oleh faktor lain yang tidak dimasukkan dalam model analisis ini, seperti modal dan bibit ternak.

\section{KESIMPULAN DAN SARAN}

Berdasarkan hasil penelitian dapat disimpulkan bahwa biaya produksi dalam pemeliharan ternak sapi di lokasi penelitian rata-rata sebesar Rp. 6,756,215,67 per tahun untuk pemeliharan 3-4 ekor yang meliputi biaya pakan $(50,20 \%)$, biaya tenaga kerja $(46,36 \%)$ dan biaya obat-batan/vitamin $(1,44 \%)$. Biaya produksi berpengaruh nyata pada tingkat signifikan $99 \%\left(\mathrm{t}_{\text {hit }}=\right.$ 0,0003) terhadap tingkat keuntungan ternak sapi di Kecamatan Suluun Tareran.

Saran yang disampaikan, perlu dilakukan kajian penelitian tentang analisis factor sosial ekonomi yang 
mempengaruhi usaha pemeliharaan ternak sapi berorientasi agribisnis.

\section{DAFTAR PUSTAKA}

BP3K. 2012. BP3K Desa Suluun Kecamatan Suluun Tareran Kabupaten Minahasa Selatan.

Direktorat Jenderal Peternakan. 2003. Upaya Peningkatan Pendapatan Petani Melalui Integrasi Usaha Peternakan Pada Usahatani Lahan Sempit. Direktorat Jenderal Peternakan, Jakarta

Elly, F.H, B.M Sinaga, S.U. Kuntjoro, N. Kusnadi, 2008. Pengaruh Biaya transaksi terhadap Prilaku Ekonomi Rumah Tangga Petani Peternak Sapi Potong Di Kabupaten, Forum Pascasarjana Vol. 32 No. 3 Juli 2009 :195-213.

Gujarati, D. 1995. Ekonometrika Dasar. Penerbit Erlangga, Ciracas-Jakarta (Anggota Ikapi).

Sugeng, S. 2000. Pemeliharaan ekstensif dan intensif ternak sapi. Penerbit Erlangga, Jakarta.
Suratyah, K. 2009. Ilmu Usaha Tani.Jakarta: Penebar Swadaya.

Susilorini, T.E. 2000. Budi Daya 22 Ternak Potensial. Penebar Swadaya. Jakarta. 
